\title{
Mısır yetiştiriciliğinde sırta ekimde farklı tohum yatağı hazırlama yöntemlerinin ekim kalitesine etkisi
}

\section{Effects of different seedbed preparation methods performing ridge sowing technique on sowing quality in maize cultivation}

\author{
Ali BOLAT \\ Doğu Akdeniz Tarımsal Araştırma Enstitüsü Müdürlüğü, Adana \\ Sorumlu yazar (Corresponding author): A. Bolat, e-posta (e-mail): bolat.ali@tarimorman.gov.tr \\ Yazar(lar) e-posta (Author e-mail): hakaraagac@ hotmail.com
}

\section{MAKALE BILGİSİ}

Alınış tarihi 30 Mayıs 2018

Düzeltilme tarihi 10 Ocak 2019

Kabul tarihi 21 Mart 2019

\section{Anahtar Kelimeler:}

Misir

Ana ürün

Toprak işleme

Bitki dağılım düzgünlüğü

Çıkış yüzdesi

\begin{abstract}
ÖZ
$\mathrm{Bu}$ araştırma, 2012ve 2013 yıllarında mısır bitkisi yetiştiriciliğinde tohum yatağı hazırlığı için farklı tohum yatağı hazırlama yöntemlerinin tarla filliz çıkış derecesi (çıkış yüzdesi) ve bitki dağılım düzgünlüğünü (ikizlenme oranı, boşluk oranı, kabul edilebilir bitki aralı̆̆ı oranı) belirlemek üzere gerçekleştirilmiştir. Çalışmada sırt tazeleme + sırt tapanı + ekim (Y1), sırt tazeleme + ekim (Y2) ve sirta doğrudan ekim (Y3) olmak üzere 3 farklı konu değerlendirmeye alınmıştır. Çalışmanın her iki yılında da ikizlenme oranı, boşluk oranı, kabul edilebilir bitki aralı̆̆ oranı ve çıkış yüzdesi değerleri istatistiksel olarak önemli bulunmuştur. Y1 yöntemi, araştırmanın her iki yılında da en yüksek performans değerlerini göstermiş̧tir.
\end{abstract}

\section{ARTICLE INFO}

Received 30 May 2018

Received in revised form 10 January 2019

Accepted 21 March 2019

\section{Keywords:}

Maize

Main crop

Tillage

Uniformity of plant distribution

The values of emergence percentage

\begin{abstract}
This research was conducted to determine the values of emergence percentage and the plant emergence performance (multiple index, miss index, the quality of feed index) of different tillage methods for maize plant seed bed preparation in 2012 and 2013 years. In study was investigated the applications 3 different methods; ridge refresh + ridge worshiper + sowing (Y1), ridge refresh + sowing (Y2) and to ridge direct sowing (Y3) have researched. In both years of the study, miss index, the quality of feed index and the values of emergence percentage except multiple index were found to be statistically significant. In both years of the study, the highest performance values were obtained from the Y1 method.
\end{abstract}

\section{Giriş}

Mısır, dünyada tahıllar içinde ekiliş alanı bakımından üçüncü, üretim açısından ilk sırada yer alan önemli bir tahıl bitkisidir. Ülkemizde de hayvan yemi ve insan gıdası olarak kullanılan mısır bitkisi, buğday ve arpadan sonra en fazla ekim alanı ve üretim miktarına sahiptir (Anonim 2018a).

Dünyada üretilen misırın \% 27'si insan beslenmesinde, $\%$ 73'ü ise hayvan yemi olarak kullanılmaktadır. Gelişmekte olan ülkelerde mısırın kullanımı hayvan beslenmesinde \% 46, insan beslenmesinde ve sanayi hammaddesi olarak \% 54'dir. Gelişmiş ülkelerde ise bu oran hayvan beslenmesinde \% 90, insan beslenmesinde ve sanayi hammaddesi olarak \% 10'dur (Anonim 2018b).
Ülkemizin hemen her bölgesinde tarımı yapılan misır bitkisi, Türkiye tarımında önemli bir paya sahiptir (Bayram 2010). Ülkemizde mısır bitkisi üretiminin en çok yapıldığ 1 alanlardan birisi de Çukurova ovasıdır. Çukurova'da mısır genellikle ana ürün olarak ekilip üretilmekte ve çoğunlukla sırta ekim yöntemi uygulanmaktadır. Sırta ekimde hazırlanan toprak sırt uygulaması, bir önceki yılın sonbaharında oluşturulmakta, havanın ve topraktaki yabancı otların durumuna göre kışın tazelenmektedir. İlkbaharda misır ekimi öncesi topraktaki yabancı otların durumuna göre sırt ikinci kez yenilenmektedir. Misır yetiştiriciliğinde toprak işleme yöntemleri ile ilgili birçok farklı çalışma bulunmaktadır. 
Karayel ve Özmerzi (2005), misır ve karpuz tohumları kullanılarak, hassas ekimde gömücü ayakların (balta, çapa, tek diskli ve çift diskli) tohum dağılımlarını belirlemek için yapmış oldukları çalışmada, her iki tohum ile yapılan denemelerde gerek yatay ve gerekse düşey düzlemdeki dağılım açısından en iyi gömücü ayağın balta gömücü ayak olduğunu saptamışlardır.

Dede (2007), ikinci ürün silajlık misırda yaptığı bir çalışmada, geleneksel toprak işleme yöntemi ve azaltılmış toprak işleme yöntemi üzerinde düze ekim ve sırta ekimi karşılaştırmıştır. Çalışmada en yüksek çıkış yüzdesi değeri, azaltılmış toprak işleme yönteminin sırta ekiminde, en yüksek verim değeri ise azaltılmış toprak işleme yönteminin düze ekiminde elde edilmiştir.

Sırta ekimde düze ekime göre daha yüksek bitki çıkışı sağlandığı için, yüksek bitki çıkışı sağlayan bir ekim makinası ile yapılacak sırta ekimde bitki çıkışı açısından daha büyük avantajların sağlanabileceğini bildirmişlerdir (Altuntaş ve Dede 2009; Yazg1 ve ark. 2017).

Yalçın ve ark. (2009), ikinci ürün mısır tarımında yaptıkları bir çalışmada, geleneksel düze ekim ve sırta ekim yöntemlerini karşılaştırmışlardır. Deneme sonucunda, bitki boyu ve verim bakımından ekim yöntemleri arasında önemli farklılıkların olduğu tespit edilmiştir.

Barut ve Çelik (2010), ikinci ürün mısırda toprak işleme yapılan ve toprak işlemesiz parsellerde bitki çıkışı ve verim üzerine oluşan etkileri incelemişlerdir. Toprak işleme yapılan parsellerde bitki çıkış1 \% 94 'ün üzerinde değerler göstererek daha yüksek sonuçlar göstermiştir.

Çakır ve ark. (2010), Aşağı Menemen ovasında mısır ve arpa-fiğ üretiminde azaltılmış toprak işleme, kültürel işlemler için toprak işlemenin yapıldığı doğrudan ekim ve hiçbir toprak işlemenin yapılmadığı toprak işlemesiz doğrudan ekim tekniklerini geleneksel toprak işlemeyle karşılaştırmışlardır. Çalışma sonunda goble diskaronun kullanıldığı azaltılmış toprak işleme sistemi en yüksek verime sahip olurken sıfir toprak işlemede en düşük verimin alındığ 1 görülmüştür.

Yazg1 ve ark. (2017) baltalı ve diskli gömücü ayağa sahip ekim makinalarının sırta ekim performansları bitki dağılım düzgünlüğ̈̈ ve tarla filiz çıkış derecesi yönünden laboratuvar ve tarla koşullarında karşılaştırılmıştır. Çalışma sonuçlarına göre, disk ayaklı ekim makinaları ile tarla filiz çıkış derecesi, kabul edilebilir bitki aralığı oranı ve ikizlenme oranı değerleri daha iyi sonuçlar göstermiştir.

$\mathrm{Bu}$ çalışmada, ana ürün misır bitkisinin sırta ekiminde sonbaharda hazırlanmış ve kış döneminde tekrar yenilenmiş / tazelenmiş olan sırt tohum yatağına, ana ürün mısırın ekim zamanı olan ilkbahar döneminde yapılan farklı toprak işleme uygulamalarının bitki dağılım düzgünlüğü (ikizlenme oranı, boşluk oranı, kabul edilebilir bitki aralığı) ve çıkış yüzdesine olan etkilerinin belirlenmesi amaçlanmıştır.

\section{Materyal ve Yöntem}

Bu çalışma 2012 ve 2013 üretim sezonlarında Adana ili Doğu Akdeniz Tarımsal Araştırma Enstitüsü Müdürlüğü'ne bağlı Hacıali İşletmesi deneme alanında yürütülmüştür. Denemenin yapıldığı toprak killi tınlı yapıya sahip olup, organik madde içeriği düşüktür. Uzun yıllar ortalamasında yıllık yağış miktarı $644.6 \mathrm{~mm}$, ortalama sicaklık yaklaşık $19.1^{\circ} \mathrm{C}$ civarındadır (Anonim 2018c). Araştırma kapsamında toprağın işlenmesi için merdaneli çizel, yöntemlere ait sırtların oluşturulabilmesi amaciyla sırt listeri ve sırt tapanı ekipmanları kullanılmıştır. Denemelerde ekim makinesi olarak, 6 sıralı disk ayaklı pnömatik hassas ekim makinesi kullanılmıştır. Ekim makinasının ekici ünitelerinde her bir delik çapı $4.5 \mathrm{~mm}$ olan 26 adet delikli plakalar kullanılmıştır. Ekim işleminde traktör ilerleme hızı $6 \mathrm{~km} \mathrm{~h}^{-1}\left(1.67 \mathrm{~m} \mathrm{~s}^{-1}\right)$ ekim makinasının vakum basınc1 60 mbar $(6 \mathrm{kPa})$ olarak seçilmiştir. Tarımsal ekipmanların (çizel, sırt listeri, sırt tapanı, ekim makinası) uygulanmasında $73 \mathrm{~kW}$ gücünde bir traktör kullanılmıştır. Ekimde sira üzeri mesafe $70 \mathrm{~cm}$, sira arası mesafe $17.3 \mathrm{~cm}$, ekim derinliği ekim makinası üzerinde $5 \mathrm{~cm}$ olarak ayarlanmış ve taban gübresi olarak ekim anında $15 \mathrm{~kg} \mathrm{da}^{-1}$ DAP gübresi uygulanmıştır.

Deneme tesadüf blokları deneme desenine göre 3 tekerrürlü olarak kurulmuştur. Denemede parsel büyüklükleri $63 \mathrm{~m}^{2}$ (4.2 m x 15 m) ölçülerindedir. Deneme öncesi tüm parsellerde sonbahar dönemi toprak hazırlığında merdaneli çizel 2 defa çapraz olarak uygulanmıştır. Sonrasında sırt listeri ile sırtlar oluşturulmuştur. Oluşturulan sırtların tamamı kış dönemi içerisinde yabancı otlara karşı yenilenmiştir. Tohum ekim zamanı olan ilkbahar döneminde ise bu sırtlara aşağıdaki uygulamalar yapılmıştır.

\section{Y1- Sirt Tazeleme (yenileme) + Sirt Tapan1 + Misır Ekimi \\ Y2- Sirt Tazeleme (yenileme) + Misır Ekimi \\ Y3- Misır Ekimi}

İlkbahar döneminde farklı tohum yatağı hazırlama yöntemlerinin, tohum dağglım düzgünlügüne ve çıkış yüzdesine olan etkilerini belirlemek amaciyla, deneme parsellerinde bitki çıkışı sabitlendikten sonra tesadüfi olarak seçilen $5 \mathrm{~m}$ uzunluğundaki üç sıra üzerinde, bitki sayımları yapılmıştır. Bu sayımlardan bitki dağılım düzgünlüğü belirlemek için boşluk oranı, ikizlenme oran1, kabul edilebilir bitki aralığı oranı ve çıkış yüzdesi değerleri hesaplanmıştır (Barut 1996). Hesaplanan değerlerden bitki dağılım düzgünlüğü Çizelge 1'de verilen skalaya bağlı olarak değerlendirmeye alınmıştır (Aykas ve ark. 2013; Yazg1 ve ark. 2017).

Çizelge 1. Bitki dağılım düzgünlüğü oranlarının değerlendirmesi.

Table 1. Evolation of the seed spacing accuracy ratio.

\begin{tabular}{cccc}
$\begin{array}{c}\text { Kabul Edilebilir Bitki } \\
\text { Aralıkları Oranı } \\
(\text { KBAO, \%) }\end{array}$ & $\begin{array}{c}\text { İkizlenme } \\
\text { Oranı (IO), \%) }\end{array}$ & $\begin{array}{c}\text { Boşluk Oranı } \\
(\mathrm{BO}, \%)\end{array}$ & Değerlendirme \\
\hline$>98.6$ & $<0.7$ & $<0.7$ & Çok İyi \\
$>90.4-\leq 98.6$ & $\geq 0.7-<4.8$ & $\geq 0.7-<4.8$ & İyi \\
$\geq 82.3-90.4$ & $\geq 4.8-\leq 7.7$ & $\geq 4.8-\leq 10$ & Orta \\
$<82.3$ & $>7.7$ & $>10$ & Yetersiz \\
\hline
\end{tabular}

Sıra üzerindeki iki bitki arasındaki mesafe, ekim makinasının anma tohum aralığının 1.5 katından daha fazla olması boşluk oranı olarak, ekim makinasının anma tohum aralığının 0.5 katından daha az olması ikizlenme oranı, ekim makinasının anma tohum aralığının 0.5-1.5 katı arası olması kabul edilebilir bitki aralığı oranı olarak adlandırılır ve aşağıdaki eşitlikler yardımıyla hesaplanır.

$\mathrm{BO}=(\mathrm{no} / \mathrm{n}) 100$
$\mathrm{IO}=(\mathrm{n} 2 / \mathrm{n}) 100$
$\mathrm{KBAO}=(\mathrm{n} 1 / \mathrm{n}) 100$
$\mathrm{ÇY}=(\mathrm{Nb} / \mathrm{N}) 100$ 
Burada;

BO: Boşluk oranı (\%),

İO: İkizlenme oranı (\%),

KBAO: Kabul edilebilir bitki aralığı oranı (\%),

Z: Sira üzeri mesafe $(\mathrm{cm})$,

$\mathrm{n}$ : Toplam bitki aralığı sayısı (adet),

no: $1.5 \mathrm{Z}$ 'den büyük bitki aralıkları sayısı (adet),

n1: (0.5-1.5) $\mathrm{Z}$ arasındaki bitki aralıkları sayısı (adet),

n2: 0.5 Z'den küçük bitki aralıkları sayısı (adet),

ÇY: Çıkış Yüzdesi,

$\mathrm{Nb}$ : Birim uzunlukta çıkan bitki sayısı (bitki $\mathrm{m}^{-1}$ ),

$\mathrm{N}$ : Birim uzunluğa ekilen tohum sayısı (tohum $\mathrm{m}^{-1}$ )'dır.

Her iki yıl için, ekim yatağı hazırlama yöntemlerinin bitki dağılım düzgünlüğü ve bitki çıkışına etkileri varyans analizine göre belirlenmiş ve ortalamalar arası farklılıklar ise Lsd çoklu karşılaştırma testi ile ortaya konulmuştur.

\section{Bulgular}

Araştırma kapsamında birinci y1l (2012 y1lı) için her bir yöntemin boşluk oranı, ikizlenme oranı, kabul edilebilir bitki aralığı oranı ve çıkış yüzdesi değerleri Çizelge 2'de, ikinci yılında (2013 yılı) elde edilen değerler Çizelge 3'te verilmiştir.

Çizelge 2 incelendiğinde farklı tohum yatağı hazırlama yöntemlerinin boşluk oranı (BO) ve ikizlenme oranı (İO) üzerine etkisi istatistiksel olarak \% 1 seviyesinde önemli, kabul edilebilir bitki aralığı oranı (KBAO) ve çıkış yüzdesi (ÇY) üzerine etkisi istatistiksel olarak \% 5 seviyesinde önemli bulunmuştur. En düşük BO değeri \% 2.4 ile Y1 yönteminde, en yüksek BO değeri \% 7.1 ile Y3 yönteminde elde edilirken, en düşük İO değeri \% 3.5 ile Y1 ve Y2 yönteminde, en yüksek İO değeri \% 6.5 ile Y3 yönteminde elde edilmiştir. En yüksek KBAO değeri \% 94.1 ile Y1 yönteminde elde edilirken, bunu \% 91.9 değeri ile istatistiksel olarak aynı grupta yer alan Y2 yöntemi takip etmiştir. En düşük KBAO değeri \% 86.4 ile Y3 yönteminde elde edilmiştir. En yüksek ÇY değeri \% 95.8 ile Y1 yönteminde elde edilirken, bunu istatistiksel olarak aynı grupta yer alan \% 91.4 değeri ile Y2 yöntemi takip etmiştir. En düşük ÇY değeri ise, \% 88.3 ile Y3 yönteminde bulunmuştur.

Çizelge 3 incelendiğinde farklı tohum yatağı hazırlama yöntemlerin ikizlenme oran1 (İO) üzerine etkisi istatistiki olarak önemsiz, boşluk oranı (BO), kabul edilebilir bitki aralığı oranı (KBAO) ve çıkış yüzdesi (ÇY) üzerine etkisi istatistiki olarak önemli bulunmuştur. En düşük $\mathrm{BO}$ değeri $\% 6.8$ ile $\mathrm{Y} 1$ yönteminde, en yüksek $\mathrm{BO}$ değeri \% 12.1 ile Y3 yönteminde elde edilmiştir. İO değeri bakımından yöntemler arasında istatistiki fark bulunmazken en düşük değer \% 2.7 ile Y1 yönteminde, en yüksek değer \% 4.0 ile Y3 yönteminde elde edilmiştir. En yüksek KBAO değeri \% 90.5 ile Y1 yönteminde elde edilirken, bunu \% 89.3 değeri ile istatistiksel olarak aynı grupta yer alan Y2 yöntemi takip etmiştir. En düşük KBAO değeri \% 83.9 ile Y3 yönteminde elde edilmiştir. ÇY değerleri bakımından en yüksek değer \%94.3 ile Y1 yönteminde elde edilirken, bunu \% 90.2 değeri ile istatistiksel olarak aynı grupta yer alan Y2 yöntemi takip etmiştir. En düşük ÇY değeri \% 85.3 ile $\mathrm{Y} 3$ yönteminde bulunmuştur.

Denemenin yürütüldüğü ikinci yıl (2013) verilerinin, birinci yıl (2012) verilerine göre BO değerleri bakımından daha yüksek, İO değerleri bakımından daha düşük olduğu görülmektedir. Bunun sebebinin denemenin ikinci yllında yabanc1 ot yoğunluğunun daha yüksek olmasından kaynaklandığı söylenebilir. Yine aynı şekilde KBAO ve ÇY değerlerindeki düşmenin de yabancı ottan dolayı olduğu söylenebilir. Dolayısıyla yabanc1 ot oranının ekim performansını olumsuz yönde etkilediği görülmektedir.

\section{Tartışma ve Sonuç}

Bitki dağılım düzgünlüğü bakımından araştırmanın her iki yılındaki sonuçlar dikkate alındığında, birinci yıl sonuçlarında değerlendirme skalasına göre $\mathrm{Y} 1$ ve $\mathrm{Y} 2$ yöntemleri iyi düzeyde, Y3 yöntemi ise orta düzeyde kalmıştır. İkinci yıl sonuçlarında değerlendirme skalasına göre Y1 yöntemi iyi düzeyde kalmıştır.

Tarla filiz çıkış derecesi (çıkış yüzdesi) bakımından araştırmanın her iki yılında elde edilen sonuçlar arasında en yüksek değerler Y1 yönteminde elde edilmesine rağmen $\mathrm{Y} 1$ ve Y2 yöntemleri istatistiki olarak aynı grupta yer almıştır.

Tarla trafiği artmasına rağmen, mısır yetiştiriciliğinde iyi bir bitki dağılım düzgünlüğü ve yüksek çıkış yüzdesi sağlamak için Y1 ve Y2 yöntemleri tavsiye edilebilecek yöntemler olmuşlardır. Y1 yönteminin Y2 yöntemine göre biraz daha iyi sonuçlar göstermesinin nedeni toprak hazırlığında sırt tapanı kullanılması olduğu söylenebilir. Sırt tapanı ile hazırlanmış ekim yatağının, tohum-toprak temasını daha güçlü sağladığı düşünülmektedir.

Çizelge 2. Yöntemlere ait bitki dağılım düzgünlüğü ve bitki çıkış yüzdesi değerleri (2012 yıl1).

Table 2. Plant distribution uniformity and plant emergence rate of the methods (year 2012).

\begin{tabular}{ccccc}
\hline Yöntemler & BO $(\%)$ & IO $\mathbf{~ ( \% ) ~}$ & KBAO (\%) & ÇY (\%) \\
\hline Y1 & $2.4 \pm 2.20 \mathrm{~b}$ & $3.5 \pm 0.05 \mathrm{~b}$ & $94.1 \pm 2.11 \mathrm{a}$ & $95.8 \pm 2.20 \mathrm{a}$ \\
Y2 & $4.6 \pm 1.74 \mathrm{~b}$ & $3.5 \pm 0.15 \mathrm{~b}$ & $91.9 \pm 1.89 \mathrm{a}$ & $91.4 \pm 1.95 \mathrm{ab}$ \\
Y3 & $7.1 \pm 0.55 \mathrm{a}$ & $6.5 \pm 0.75 \mathrm{a}$ & $86.4 \pm 0.64 \mathrm{~b}$ & $88.3 \pm 3.17 \mathrm{~b}$ \\
\hline Lsd & $2.39^{* *}$ & $1.06^{* *}$ & $3.07 *$ & $4.50^{*}$ \\
\hline **: sütunda aynı harflerle gösterilen değerler $p<0.01$ düzeyinde farksızdır.*: sütunda aynı harflerle gösterilen değerler $\mathbf{p}<0.05$ düzeyinde farksızdır.
\end{tabular}

Çizelge 3. Yöntemlere ait bitki dağı̆lım düzgünlüğü ve bitki çıkış yüzdesi değerleri (2013 yıl1).

Table 3. Plant distribution uniformity and plant emergence rate of the methods (year 2013)

\begin{tabular}{|c|c|c|c|c|}
\hline Yöntemler & BO (\%) & İO (\%) & KBAO (\%) & ÇY (\%) \\
\hline $\mathrm{Y} 1$ & $6.8 \pm 0.36 \mathrm{~b}$ & $2.7 \pm 0.15$ & $90.5 \pm 0.40 \mathrm{a}$ & $94.3 \pm 2.23 a$ \\
\hline $\mathrm{Y} 2$ & $7.2 \pm 0.78 \mathrm{~b}$ & $3.5 \pm 3.50$ & $89.3 \pm 3.63 \mathrm{a}$ & $90.2 \pm 4.05 \mathrm{ab}$ \\
\hline Y3 & $12.1 \pm 2.40 \mathrm{a}$ & $4.0 \pm 0.44$ & $83.9 \pm 2.00 \mathrm{~b}$ & $85.3 \pm 2.46 b$ \\
\hline Lsd & $2.62 *$ & ö.d. & $5.32 *$ & $6.33^{*}$ \\
\hline
\end{tabular}

*:sütunda aynı harflerle gösterilen değerler $\mathrm{p}<0.05$ düzeyinde farksızdır. 


\section{Kaynaklar}

Altuntaş E, Dede S (2009) Emergence of silage maize as affected by conservation tillage and ridge planting systems. Agricultural Engineering International: the CIGR Ejournal. Manuscript 1363. Vol. XI. October, 2009.

Anonim (2018a) http://dergipark.gov.tr/download/article-file/417606. Erişim 01 Kasım 2018.

Anonim (2018b)

https://arastirma.tarimorman.gov.tr/ktae/Belgeler/brosurler/. Erişim 01 Kasim 2018.

Anonim (2018c) https://www.mgm.gov.tr/veridegerlendirme/il-veilceler. Erişim 11 Temmuz 2018.

Aykas E, Yalçın H, Yazgı A (2013) Balta tipi gömücü ayağa sahip tek dane ekim makinalarının farklı bölgelerde mısır ekiminde ekim performanslarının karşılaştırılması. Tarım Makinaları Bilim Dergisi 9(1): 67-72.

Barut ZB (1996) Farklı tohumların ekimlerinde kullanılan düşey plakalı, hava emişli hassas ekici düzenin uygun çalışma koşularının saptanması. Çukurova Üniversitesi Fen Bilimleri Enstitüsü Tarım Makinaları Ana Bilim Dalı, Doktora Tezi, Adana.

Barut ZB, Çelik İ (2010) Different tillage systems affect plant emergence. Stand Establishment and Yield in Wheat- Corn Rotation. Philipp Agric Scientist Vol. 93(4): 392-398. ISSN 00317454.
Bayram E (2010) İkinci ürün silajlık mısır tarımında farklı toprak işleme yöntemlerinin işletmecilik açısından karşılaştırılması. Gaziosmanpaşa Üniversitesi Fen Bilimleri Enstitüsü Tarım Makineleri Anabilim Dalı. Yüksek Lisans Tezi. Tokat.

Çakır E, Aykas E, Yalçın H, Çay A, Dereli İ (2010) Ege bölgesinde azaltılmış toprak işleme ve doğrudan ekim uygulamalarının mısır ve arpa-fiğ verimine etkileri. 26. Tarımsal Mekanizasyon Ulusal Kongresi, 22-23 Eylül 2010, s. 16, Hatay.

Dede S (2007) Farklı toprak işleme ve ekim tekniklerinin ikinci ürün silajlık mısır tarımında toprak özellikleri ve verim üzerine etkilerinin belirlenmesi. Gaziosmanpaşa Üniversitesi Fen Bilimleri Enstitüsü Tarım Makinaları Anabilim Dalı, Yüksek Lisans Tezi, Tokat.

Karayel D, Özmerzi A (2005) Hassas ekimde gömücü ayakların tohum dağılımına etkisi. Akdeniz Üniversitesi Ziraat Fakültesi Dergisi 18(1): 139-150.

Yalçın İ, N Topuz, İ Yavaş, A Ünay (2009) İkinci ürün mısırda sırta ekim yönteminin uygulanabilirliğinin belirlenmesi. ADÜ Ziraat Fakültesi Dergisi 6(1): 35-40.

Yazgı A, Yalçın H, Aykas, E, Tozan, M (2017) Baltalı ve diskli gömücü ayağa sahip tek dane ekim makinalarının sırta ekim performanslarının karşılaştırılması. Tarım Bilimleri Dergisi 23: 195-207. 